\title{
Spine radiograph in dysplasias: A pictorial essay
}

\section{Pavan Gabra, Manisha Jana, Priyanka Naranje, Neerja Gupta', Madhulika Kabra , Arun K Gupta, Richa Yadav}

Departments of Radiodiagnosis and 'Paediatrics (Division of Genetics), All India Institute of Medical Sciences, Ansari Nagar, New Delhi, India

Correspondence: Dr. Manisha Jana, Department of Radiodiagnosis, All India Institute of Medical Sciences, Ansari Nagar, New Delhi-110 029, India. E-mail: manishajana@gmail.com

\section{Abstract}

Spine radiograph is an essential component of a skeletal survey. It provides important diagnostic clues to various types of skeletal dysplasia. In some conditions, a spine radiograph alone may be diagnostic and characteristic; but mostly, it yields more value as a part of the complete skeletal survey. In this article we will discuss about a few common lethal and non-lethal skeletal dysplasias and their characteristic imaging findings; primarily focusing on the spine radiograph.

Key words: Achondroplasia; mucopolysaccharidosis; radiograph; skeletal dysplasia; spine

\section{Introduction}

The vertebral column is composed of vertebrae and surrounding ligaments. The dorsolumbar spine (AP and lateral views) radiographs are an essential part of any skeletal survey done to look for skeletal dysplasias. The rapidly evolving pediatric body makes the knowledge of normal imaging appearance of pediatric spine across the temporal spectrum an indispensable tool to look for any abnormality.

\section{Ossification Centers}

Each vertebra has three ossification centers: one in the vertebral body and one each for a half of the neural arch, at the base of the corresponding transverse process. ${ }^{[1]}$ The ossification in the vertebral bodies progresses independent to that in the neural arches. Ossification centers of the centra appear in the lower thoracic region and progress in a cephalocaudal direction, unlike that of the neural arches. ${ }^{[2]}$

\begin{tabular}{|c|c|}
\hline \multicolumn{2}{|c|}{ Access this article online } \\
\hline Quick Response Code: & \\
\hline & $\begin{array}{l}\text { Website: } \\
\text { www.ijri.org }\end{array}$ \\
\hline & $\begin{array}{l}\text { DOI: } \\
\text { 10.4103/ijri.IJRI_395_20 }\end{array}$ \\
\hline
\end{tabular}

They appear in the upper cervical, cervicothoracic and thoracolumbar locations. All three ossification centers are present by the $5^{\text {th }}$ month of intrauterine life..$^{[1]}$

\section{Normal Appearance in Different Age Group}

At birth, the centra are united with the neural arches by a synchondrosis. The arches unite with the vertebral bodies beginning in the first year of life, with the upper lumbar vertebrae. Unification in the cervical vertebrae happens typically in the third year. Lower lumbar vertebrae are usually the last to unite, by the end of $6^{\text {th }}$ year. ${ }^{[2]}$

The secondary centers appear first during puberty, in five locations for each vertebra: one at the tip of each transverse process, one at the tip of spinous process and one each at the superior and inferior endplates of

This is an open access journal, and articles are distributed under the terms of the Creative Commons Attribution-NonCommercial-ShareAlike 4.0 License, which allows others to remix, tweak, and build upon the work non-commercially, as long as appropriate credit is given and the new creations are licensed under the identical terms.

For reprints contact: WKHLRPMedknow_reprints@wolterskluwer.com

Cite this article as: Gabra P, Jana M, Naranje P, Gupta N, Kabra M, Gupta AK et al. Spine radiograph in dysplasias: A pictorial essay. Indian J Radiol Imaging 2020;30:436-47.

Received: 20-May-2020 Revised: 31-Jul-2020 Accepted: 11-Aug-2020 Published: 13-Jan-2021 
vertebral bodies. The variation in normal appearances is shown in Figure 1.

\section{Specific Disease Entities}

Skeletal dysplasias are a very heterogeneous group of disorders with 461 different disorders classified into 42 groups, based on genotypes and phenotypes. ${ }^{[3]}$ Skeletal survey is an integral part of assessment of skeletal dysplasias..$^{[4]}$ While assessing spine radiograph as a part of skeletal survey, a systematic approach is to be adopted. ${ }^{[5]}$ After assessing whether it is a generalized/localized abnormality in the spine; the spine radiograph should be assessed for the state of ossification, segmentation anomaly, flattening (platyspondyly), or specific morphologic changes. Here in this article, we will describe disease entities subcategorized depending on their bone density. We shall highlight those diseases where spine radiograph is diagnostic; either alone or in combination with a few other radiographs.

Diseases with uniform/generalized affection of the entire vertebral column

This category can be subdivided into three groups: diseases with normal, decreased, and increased bone density. Individual groups are described separately.

\section{Diseases with normal bone density}

Achondroplasia

One of the commonest skeletal dysplasia in clinical practice; this disorder shows some characteristic imaging findings. Spine radiograph alone can be suggestive; and sometimes diagnostic of this disease entity. Classical imaging findings include progressive narrowing of interpedicular distance in lumbar vertebrae, narrow pedicles causing spinal canal stenosis, posterior scalloping of vertebral bodies, and "bullet vertebra" at dorsolumbar junction [Figure 2]. ${ }^{[6]}$ Other findings include an exaggerated lumbar lordosis and horizontally oriented sacrum. Other radiographs may show classical findings as well [Table 1].

\section{Hypochondroplasia}

The clinical phenotype and radiological findings are similar to achondroplasia; but findings are usually mild. Spine and cranial radiographs may show only mild changes [Figure 3]. ${ }^{[7]}$

\section{Thanatophoric dysplasia}

This is a lethal skeletal dysplasia, allelic to achondroplasia but having more severe presentation. It can be detected on prenatal ultrasonography in view of severe micromelia.
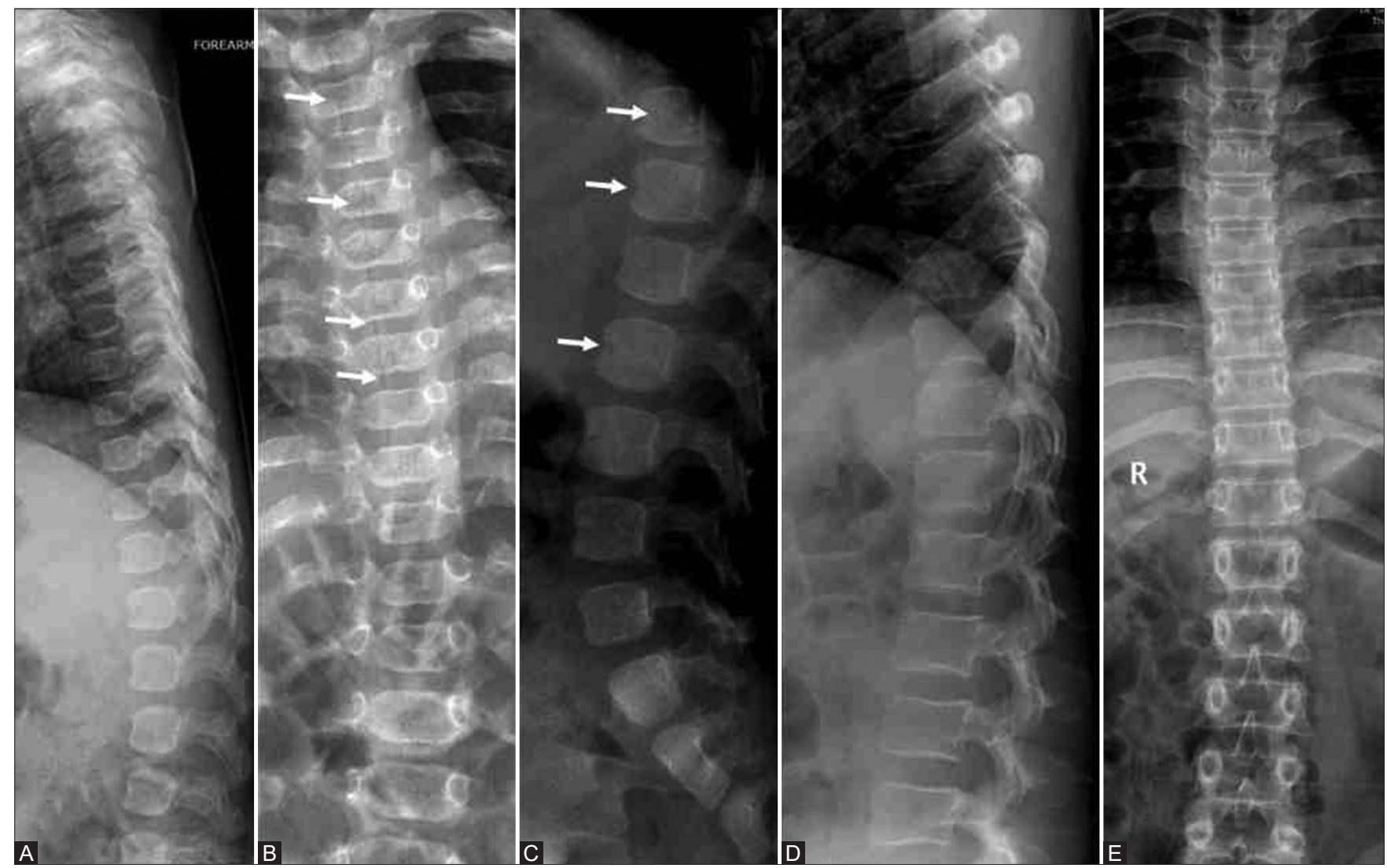

Figure 1 (A-E): (A-E) Normal appearances across various ages. (A and B) Normal appearance in 6 month girl. Note the globular shape of lumbar vertebral bodies; and lucencies overlying thoracic vertebrae (arrow in B) which can mimic spina bifida. This appearance is due to unossified cartilage of the spinous process. (C) Normal infant. Note the globular shape of vertebral bodies and an anterior concavity over the lumbar vertebral bodies (arrows). ( $\mathrm{D}$ and E) Normal 13 year old boy. Normal adult shape of the vertebrae is evident 

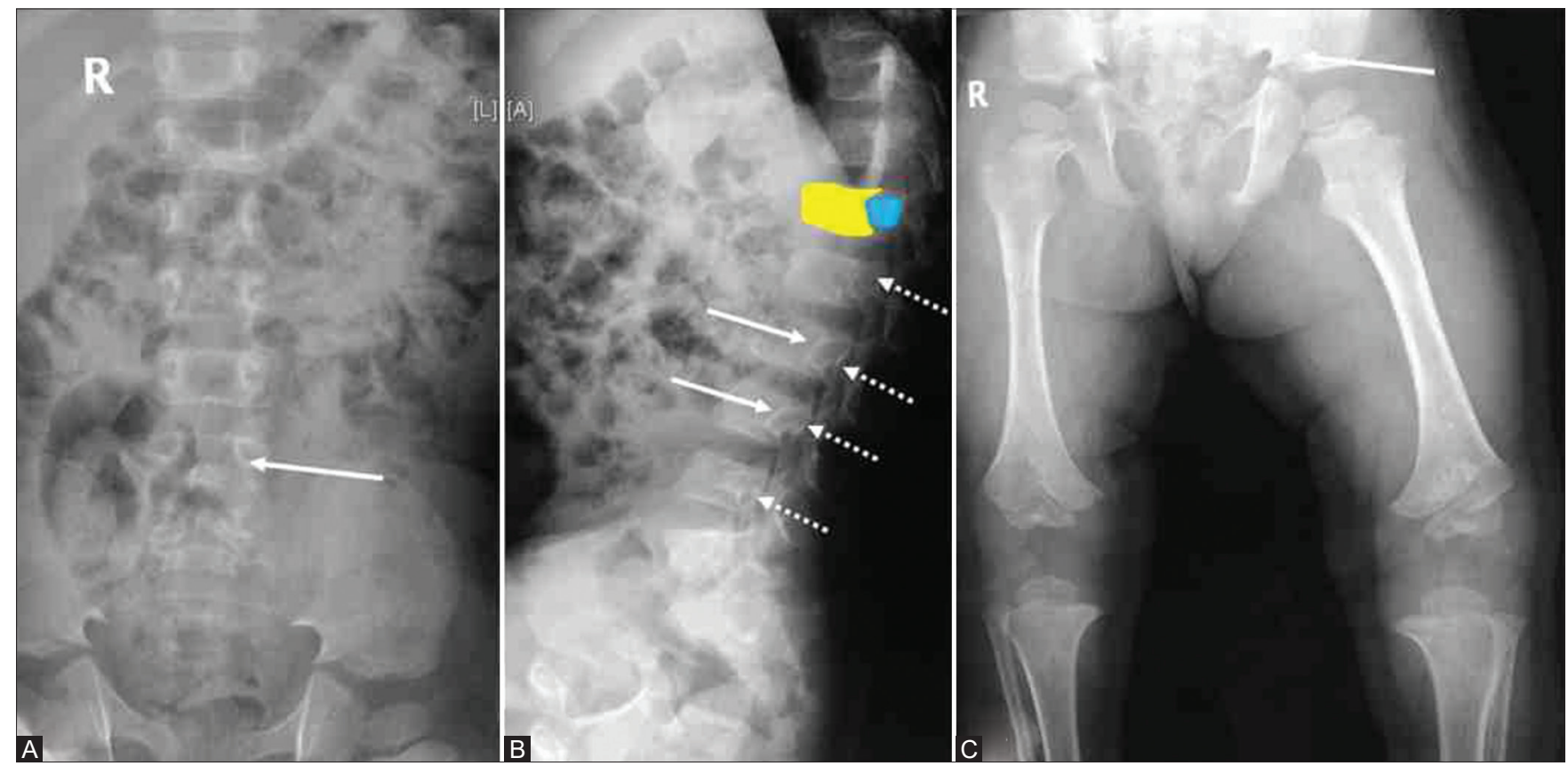

Figure 2 (A-C): (A-C) Achondroplasia. (A) Lack of progressive widening of interpedicular distance, with narrowing at L5-S1 level (arrow). Lateral spine radiograph (B) shows posterior scalloping (arrows) of vertebral bodies, narrow pedicles (dotted arrows), and classical "bullet vertebra" appearance at the dorsolumbar junction. D12 has been marked for diagrammatic depiction of morphology (yellow: vertebral body, blue: pedicle). Pelvis radiograph $(\mathrm{C})$ "tombstone pelvis", trident sign (arrow), and rhizomelic shortening

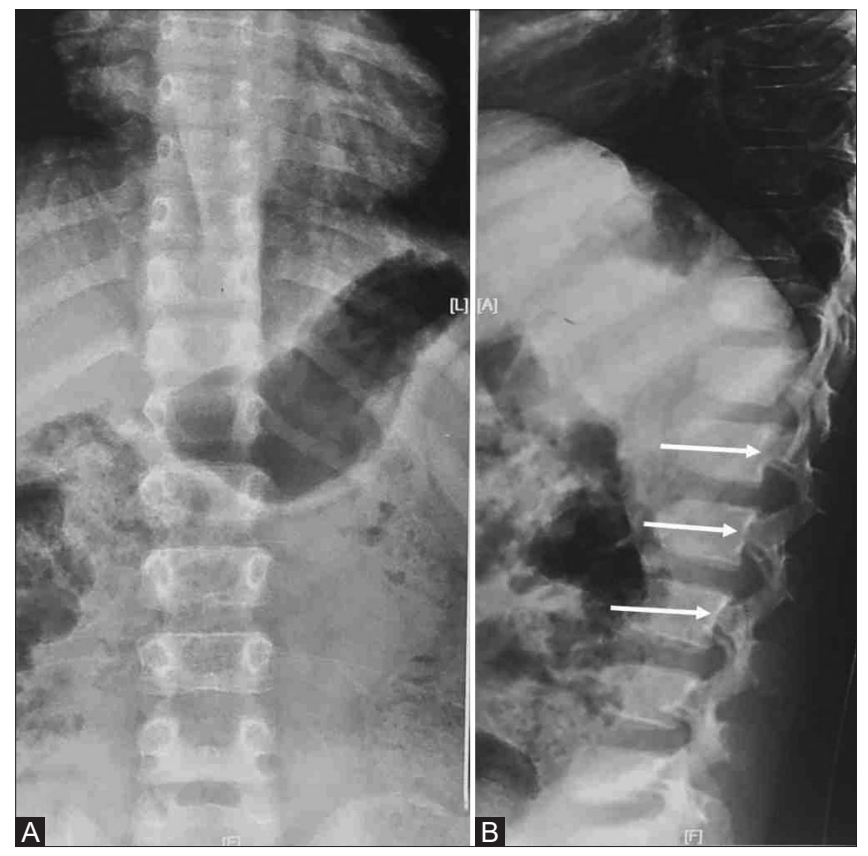

Figure 3 (A and $B$ ): (A and $B$ ) Hypochondroplasia: AP radiograph of $(A)$ showing only mild progressive narrowing of interpedicular distance. Lateral radiograph (B) shows definite, but mild, posterior vertebral body scalloping (arrows)

Typical radiographic findings [Figure 4] include "wafer-thin" vertebral bodies, bent or "telephone handle" shaped femur, trident pelvis, severe micromelia, and a deformed "cloverleaf"skull in some subtypes. ${ }^{[5]}$ The bone density is usually normal.

\section{Campomelic dysplasia}

This is a perinatally lethal dysplasia. Common imaging findings include shortening and bowing of the long bones, diaphyseal spurs, hypoplastic scapulae, narrow and "foreshortened" iliac wings, 11 pairs of ribs, and hypoplastic fibulae. The long bones in lower limb shows typical angulation; in femur at the junction of upper third and mid-third; whereas in tibia at the junction of mid and lower third.

In the spine radiograph, the typical imaging finding is absent ossification of the pedicles of thoracic vertebrae. ${ }^{[8]}$ Bone density is usually normal.

\section{Pseudoachondroplasia}

This disease entity is a variant of the spondyloepiphyseal dysplasia group of disorders. Spine as well as the epiphyses show typical imaging features. Spine radiograph reveals platyspondyly and classical central "tongue-like" projection, most prominent in the lumbar vertebrae [Figure 5]. ${ }^{[9]}$ This is to be differentiated from the central beaking of Morquio syndrome. The projection in pseudoachondroplasia is thicker/wider than that in Morquio syndrome. Other important findings in pseudoachondroplasia include prominent posterior costo-vertebral junctions, generalized epiphyseal irregularity, delayed appearance, and small size of femoral head epiphysis, wide open triradiate cartilage, metaphyseal beaking/spurs[Figure 6]. ${ }^{[9,10]}$ 
Table 1: Common imaging findings in skeletal dysplasias where spine radiograph is suggestive/diagnostic

\begin{tabular}{lll}
\hline Disease entity & Changes in spine & Other radiographs \\
\hline Achondroplasia & Progressive narrowing of interpedicular & Rhizomelic dwarfism \\
& distance in lumbar vertebrae & Short, broad 'champagne glass' pelvis with round, broad \\
& Posterior scalloping of vertebral bodies 'bullet & 'elephant ear' iliac wings \\
& vertebrae' & 'Trident sign': prominent sciatic notch \\
& Exaggerated lumbar lordosis & Chevron deformity, especially at lower femoral metaphysis \\
& Preserved bone density and vertebral body & Widely spaced 2 ${ }^{\text {nd }}$ and $3^{\text {rd }}$ metacarpals ('trident hand') \\
& height &
\end{tabular}

Thanatophoric dysplasia

Pseudoachondroplasia

MPS IV (Morquio syndrome)

Spondyloepiphyseal dysplasia congenita (SEDC)

Spondyloepiphyseal dysplasia tarda (SEDT)

Progressive pseudorheumatoid arthropathy of childhood (PPAC)

Spondylometaphyseal dysplasias (SMD)

DMC syndrome

Chondrodysplasia punctata (CDP)

Osteogenesis imperfecta

Achondrogenesis
Platyspondyly

Wide central anterior tongue like projection

Variable platyspondyly Increased intervertebral disc height

Thin anterior central beaking

Odontoid hypoplasia

Significant platyspondyly

Anisospondyly

Cervical kyphosis

Pear shaped vertebral bodies

Variable platyspondyly

Posterior hump of vertebral bodies

Mild platyspondyly

Reduced intervertebral disc height Gouge shaped anterosuperior vertebral endplate defect

Subtle vertebral endplate irregularities Mild (Sutcliffe type) to pronounced platyspondyly (Kozlowski type) Ovoid vertebral bodies (Sutcliffe type) Rounded pedicles (Kozlowski type)

Irregular constrictions at central vertebral endplates

Vertebral body stippling Coronal clefting in dorsolumbar vertebrae

Reduced bone density Biconcave codfish vertebrae Mild to severe platyspondyly (type 3) with multiple vertebral body collapses (type 3 )

Poor ossification of vertebral bodies with preserved ossification of pedicles

Platyspondyly

Widened cervical and lumbar spinal canals (type 1B)
Micromelic dwarfism with bowed (type 1) or straight (type 2) femurs \& brachydactyly

Macrocephalic clover leaf skull

Narrow thorax with short ribs

Delayed fusion of triradiate cartilage in pelvis

Very delayed appearance and development of femoral head epiphyses

Epimetaphyseal involvement

Prominent posterior costochondral junctions

Macrocephaly

Delayed carpal/tarsal and femoral head ossification with

premature arthropathy

Proximal pointing of metacarpals

Irregular epiphyses with widened metaphyses

Delayed ossification of carpals, tarsals including calcaneum, femoral head and pubic bone with premature arthropathy

Macrocephaly

Horizontal acetabular roof

Normal hands/feet

Retinal detachment, high myopia

Normal skull/hands/feet

Premature arthropathy of hips with irregular epiphyses Narrow pelvis

Metaphyseal expansion in short bones of hand and feet, especially the proximal phalanges

Metaphyseal corner fracture of long bones (Sutcliffe type)

Short stature, intellectual disability

Lacy iliac wings

Small \& irregular femoral head epiphyses

Variable stippling of multiple epiphyses of long bones, carpals and tarsals (early in life)

Irregular epiphyses with asymmetric limb shortening (late in life)

Diffuse osteopenia

Pencil thin cortices

Multiple long bone metaphyseal fractures at variable stages of healing

Macrocephaly with platybasia and Wormian bones

Hypertrophic Callus (type 5)

Interosseous membrane ossification (type 5)

Micromelic dwarfism

Unossified skull vault (type $1 \mathrm{~A} / \mathrm{B}$ )

Crescent shaped iliac wings (type $1 \mathrm{~A} / \mathrm{B}$ )

Beaded ribs (type $1 \mathrm{~A}$ ) 
Table 1: Contd...

\begin{tabular}{lll}
\hline Disease entity & Changes in spine & Other radiographs \\
\hline Hypophosphatasia & Poor ossification of both vertebral bodies and & Poor skull base ossification \\
pedicles & & Thin ribs \\
& & Metaphyseal lucencies \\
& & Diaphyseal spurs \\
& & Missing long bones (absent ossification) \\
& & Hypoplastic fibulae \\
Osteopetrosis & Increased bone density with predominant & Obliteration of medullary cavities of long bones \\
& endplate involvement ('sandwich vertebrae') & Bone within bone appearance \\
& & Multiple long bone fractures \\
Pyknodysostosis & Spool shaped vertebrae (central concavity at & Obtuse mandibular angle \\
& anterior border) & Wide open skull sutures with multiple wormian bones \\
& & Terminal acrosteolysis \\
& & Preserved medullary cavity \\
& Small pelvis with shallow acetabular cavity \\
\hline
\end{tabular}

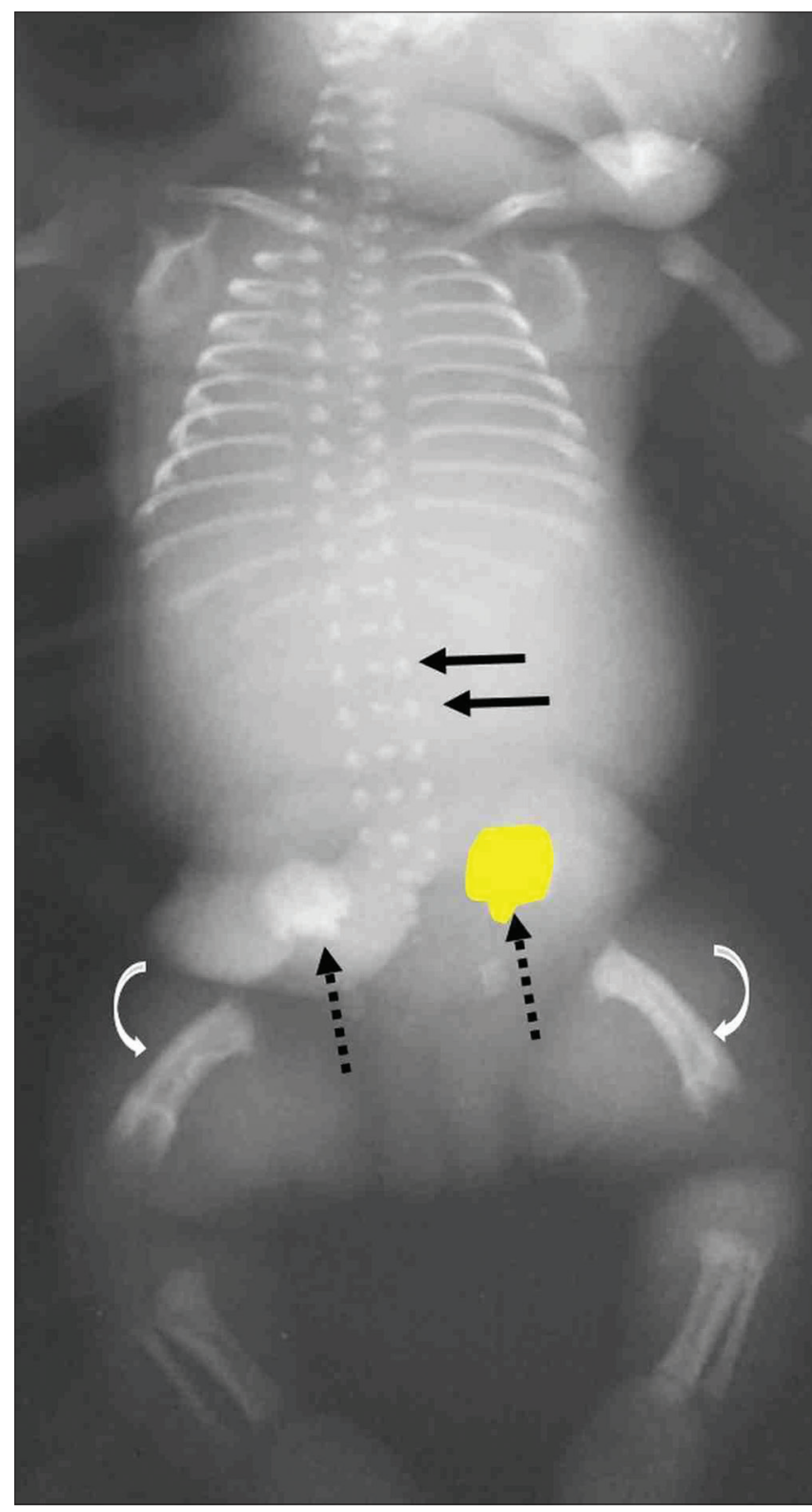

Figure 4: Thanatophoric dysplasia in a stillborn. Note well mineralized bones, "wafer thin" vertebrae (arrows), trident acetabulum (dotted arrow \& marked in yellow), and short bowed femur (curved arrows)

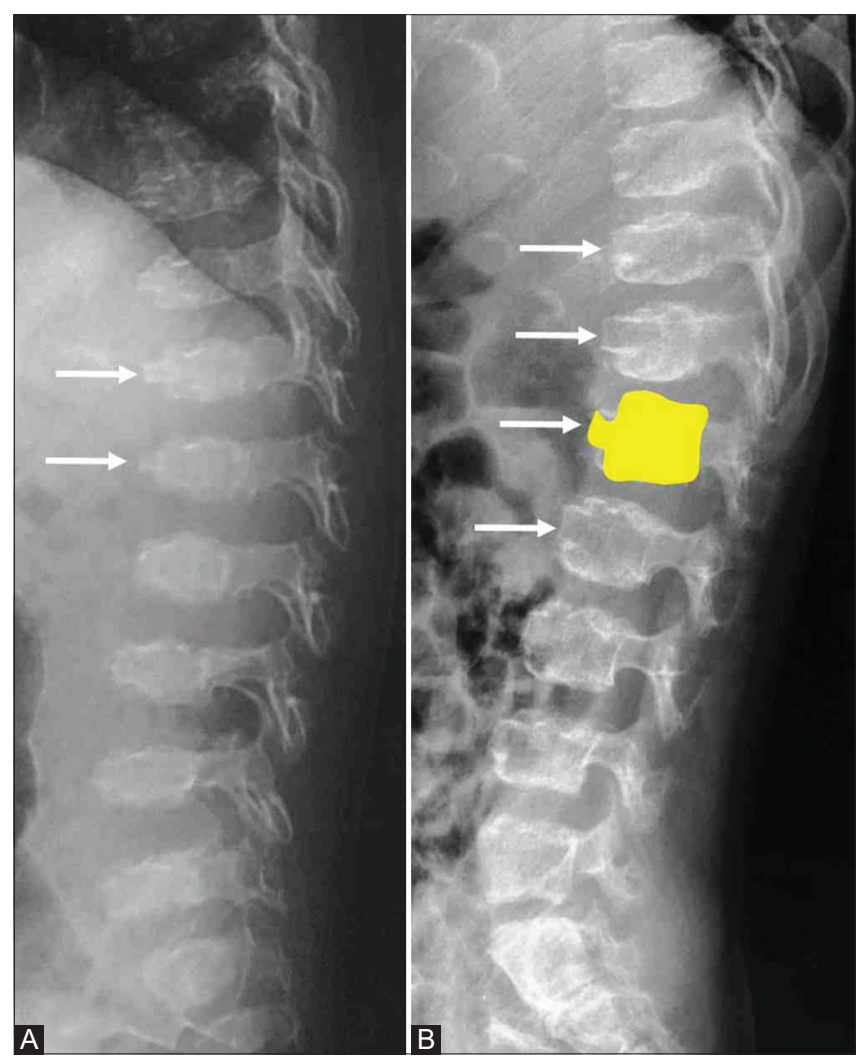

Figure 5 (A and B): (A and B) Pseudoachondroplasia. Spine radiograph in two patients. 2 year old girl (A) showing severe platyspondyly with anterior tongue-like projections (arrows); mimicking MPS IV. Seven year old girl showing more pronounced projections (arrows in B). L1 vertebral body has been marked in yellow for diagrammatic representation of morphology

\section{Mucopolysaccharidoses (MPS)}

Mostly diagnosed on the clinical phenotype and enzyme assays, this group of disorders shows typical changes in spine radiograph; as a part of "dysostosis multiplex." Usual imaging findings include variable platyspondyly, anterior vertebral beaking, odontoid hypoplasia, and maintained/increased intervertebral disc height [Figure 7]. ${ }^{[11]}$ The beaking is in anteroinferior location in MPS type 1 (Hurler's syndrome) ${ }^{[12]}$ and central 
in MPS type 4 (Morquio syndrome). ${ }^{[13]}$ Other imaging findings are listed in Table 1.

\section{Mucolipidosis (MLS)}

Several subtypes of this disease entity exists. Skeletal survey reveals imaging findings similar to MPS; with the additional finding of periosteal "cloaking" ${ }^{[14]}$ or lamellated periosteal reaction involving the long bones [Figure 8]. This typical imaging finding is most evident in infancy and disappears thereafter.

\section{Spondyloepiphyseal dysplasia congenita (SEDC)}

As evident by its name, this disease entity affects the spine and the long bone epiphyses. A disease caused by faulty collagen development (collagenopathy) ${ }^{[15]}$; this disease

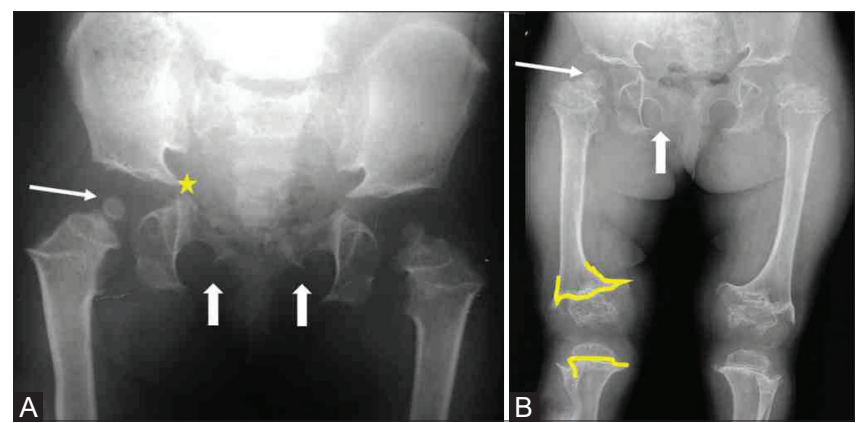

Figure 6 ( $A$ and $B)$ : (A and B) Classical appearance of pelvis in pseudoachondroplasia in different age groups. 6 year old girl (A) showing wide unossified $Y$ cartilage (asterisk), small femoral head epiphyses (arrow), unossified inferior pubic rami (block arrows). Same girl at the age of 13 years (B) show more pronounced degenerative changes around hip joints. Note that the femoral head is yet very small (arrow); $Y$ cartilage and inferior pubic rami (block arrow) still unossified. Note the typical flaring of lower femur and upper tibial metaphyses (marked in yellow)

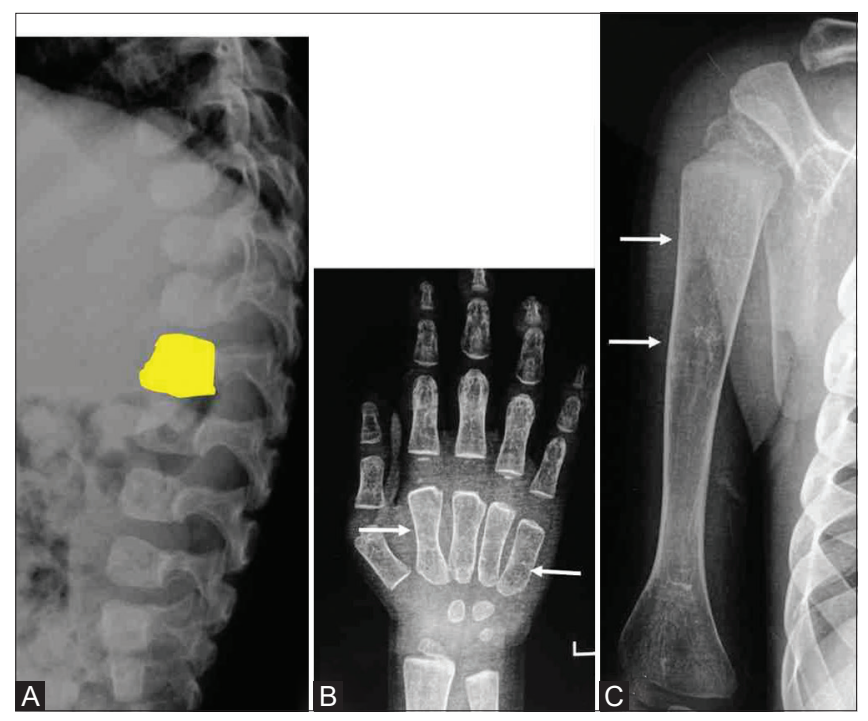

Figure 8 (A-C): (A-C) Mucolipodosis in a 3 year old boy. Globular appearance of vertebrae with subtle anteroinferior beaking (marked in yellow in A). Florid dysostosis multiplex is not seen, however medullary expansion (manifested by thinning of cortices) and undertubulation is evident in hand bones and humerus (arrows in B and C) usually manifests with a very short stature, coxa vara, waddling gait, and retinal detachment/high myopia in childhood. ${ }^{[16]}$ Radiographic findings are quite characteristic. Spine radiograph reveals significant platyspondyly, anisospondyly (variation in size of vertebral bodies), cervical kyphosis, and a pear-shaped vertebral body in smaller children/infants [Figure 9]. ${ }^{[17]}$ Other classical imaging findings include apparent pubic diastasis, coxa and vara, very delayed appearance of femoral head epiphyses, generalized epiphyseal irregularity [Table 1].

\section{Spondyloepiphyseal dysplasia tarda (SEDT)}

A very heterogeneous group of disorders, this disease also affects the spine as well as the epiphyses. However, the presentation is not as early as SEDC. Usual clinical presentation is with premature osteoarthritis involving the large joints. Many clinical variants are known to exist.
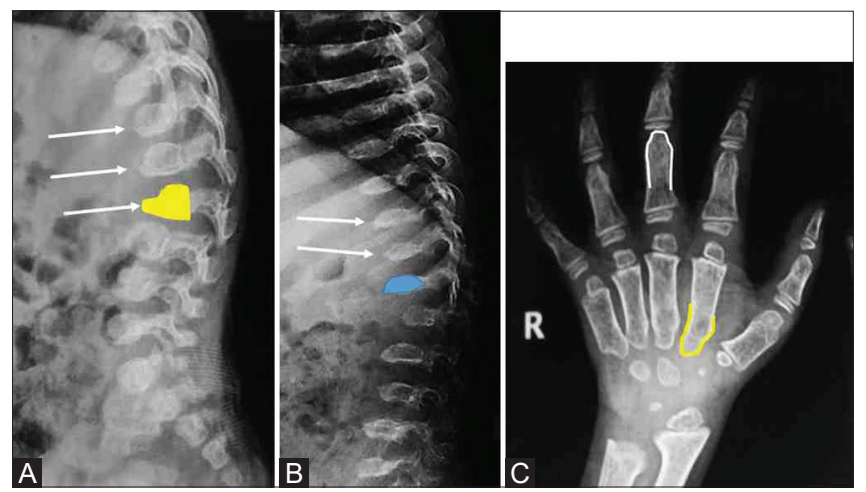

Figure 7 (A-C): (A-C) MPS 1 (A) showing typical anteroinferior beaking of lumbar vertebrae (arrows). MPS 4 (B) showing diffuse platyspondyly with thin central beaking (arrows) and widened IV disc spaces. Typical vertebral shape has been marked in yellow in a and blue in $\mathrm{b}$. Hand radiograph $(C)$ showing proximal pointing of metacarpals (marked in yellow) and "bullet shaped" phalanges (marked in white)
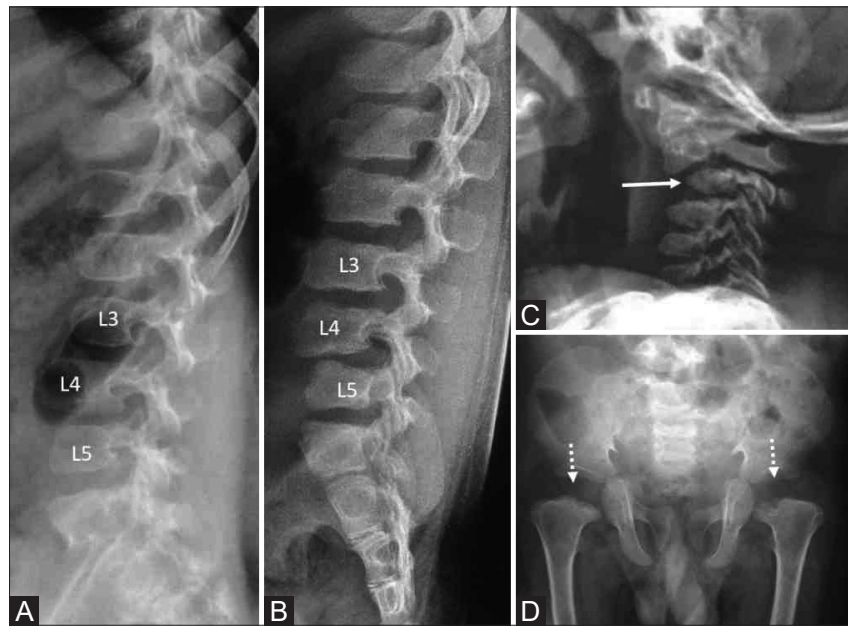

Figure 9 (A-D): (A-D) Spondyloepiphyseal dysplasia congenita (SEDC). (A and B) Anisospondyly: L4 is larger than L3 and L5 (A); L5 smaller than rest of the lumbar vertebrae (B) Cervical kyphosis (arrow) with cervical vertebral body hypoplasia (C) Apparent $\mathrm{DDH}$ in pelvis radiograph (D) in a 4 year old boy due to delayed ossification of femoral head epiphyses (dotted arrows) 
Typical imaging findings include variable platyspondyly and "posterior hump" of vertebral bodies [Figure 10]. ${ }^{[18]}$ Epiphyses of the long bones show irregular outline and early degenerative changes.

Progressive pseudorheumatoid arthropathy of childhood (PPAC) A subtype of SEDT; this disease has a unique clinical presentation with early development of painless joint contractures involving small joints of the hand. ${ }^{[19]}$ It often mimics rheumatologic condition ${ }^{[20]}$ and misdiagnosed based on clinical appearance alone. Imaging is diagnostic of this entity. Spine radiograph shows anterosuperior endplate defect (gouge shaped) with mild platyspondyly. Early development of degenerative changes and reduction of IVD spaces may occur. Diagnostic hand/feet radiographic finding is metaphyseal expansion of proximal phalanges [Figure 11]. ${ }^{[21]}$

\section{Spondylometaphyseal dysplasias (SMD)}

Various subtypes exist; with the common feature of involvement of spine as well as long bone metaphyses. The spinal changes may range from subtle endplate irregularity to platyspondyly [Figure 12]. Spondylometaphyseal dysplasia Sutcliffe type (corner fracture type) may show ovoid appearance of vertebral bodies. A distinctive feature of this entity is presence of "corner fractures" at long bone metaphyses. ${ }^{[22]}$ SMD Kozlowski type presents with a more

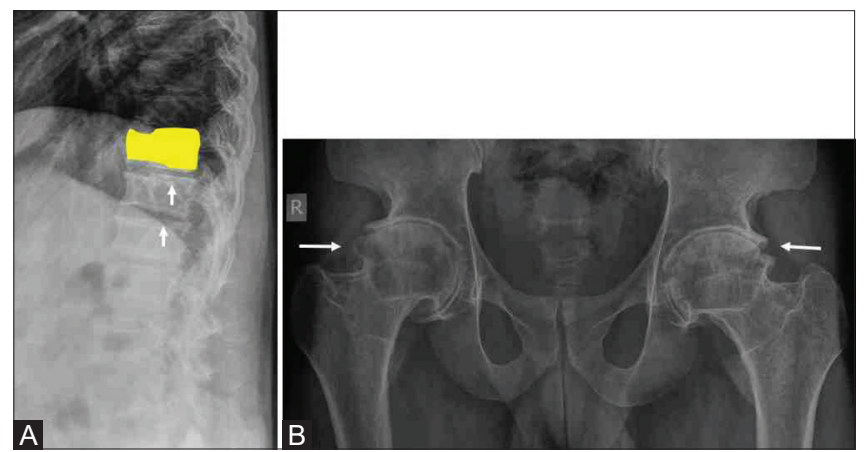

Figure 10 (A and B): (A and B) Spondyloepiphyseal dysplasia tarda (SEDT). Platyspondyly with classical "hump" at the posterior $2 / 3^{\text {rd }}$ part of vertebral bodies (arrows in A) with severe reduction of IVD spaces. Extensive early degenerative changes around hip joints (arrows in B)

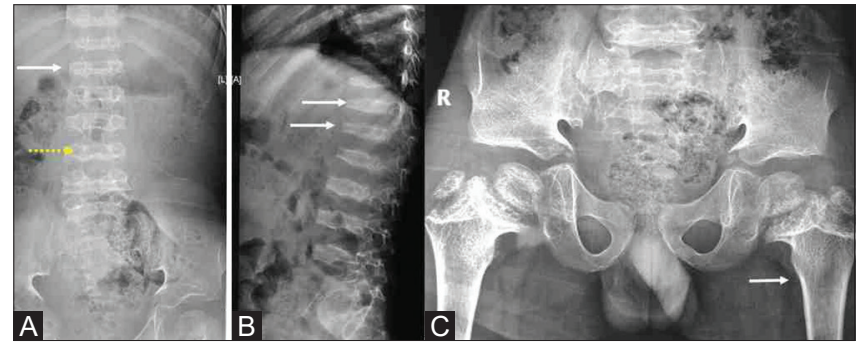

Figure 12 (A-C): (A-C) Spondylometaphyseal dysplasia Kozlowski type. Significant platyspondyly (arrows in A and B) with rounded pedicles (dotted arrow in A). Extensive metaphyseal irregularity (arrow) in proximal femur $(C)$ pronounced platyspondyly and rounded appearance of pedicles on AP spine radiograph. ${ }^{[23]}$

\section{Multiple epiphyseal dysplasia (MED)}

Multiple epiphyseal dysplasia primarily presents as generalized epiphyseal irregularity and sclerosis. ${ }^{[24]}$ The spinal changes are variable, and may be only subtle irregularity of the endplates. ${ }^{[18]}$

\section{Dyggve-Melchior Claussen syndrome (DMC)}

Clinical presentation of this rare disorder is usually with intellectual disability and short stature. Apart from the classical and characteristic "lacy iliac wings"[25]; the spinal changes also are quite suggestive. It presents as irregular constrictions at the central vertebral endplates [Figure 13].

\section{Chondrodysplasia punctata (CDP)}

Several subtypes of this disease exist. Most striking imaging appearance is stippling of the bones. ${ }^{[26]}$ This feature can be seen involving long bone epiphyses, carpal and tarsal bones and even involving the vertebral bodies. Coronal

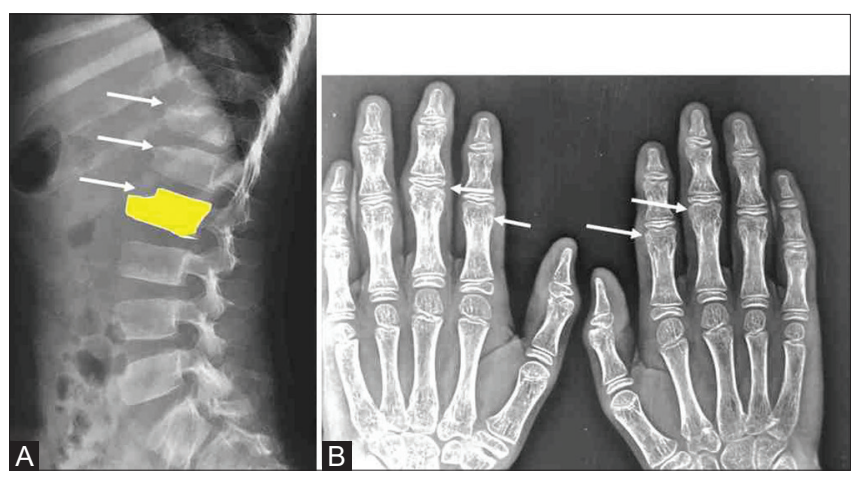

Figure 11 (A and $B$ ): (A and $B$ ) PPAC in a 10-year old boy presenting with painless contractures of small joints of hands. Typical anterosuperior endplate defects (arrows) in dorsolumbar vertebrae (A). Typical morphology marked in yellow. Classical metaphyseal expansion of the proximal phalanges (arrows in B)

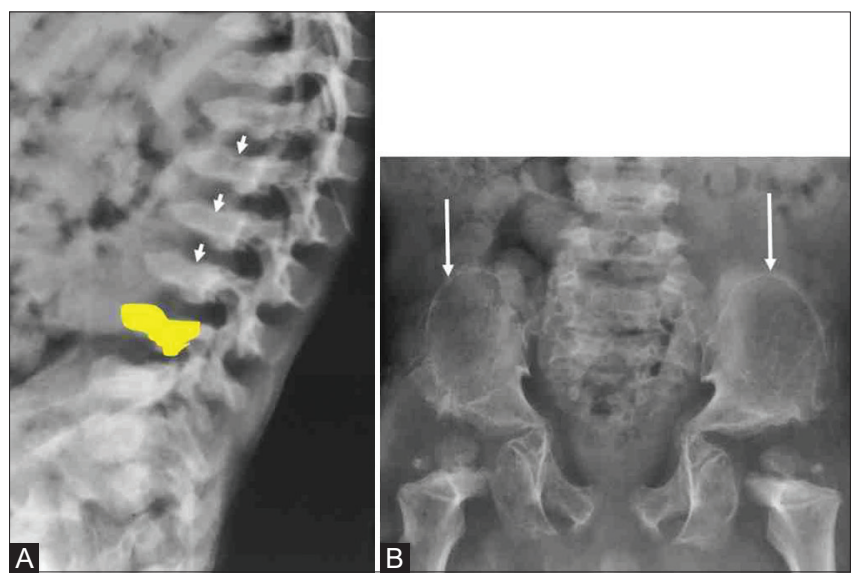

Figure 13 (A and B): (A and B) DMC in a 7-year girl with intellectual disability. Typical central endplate depression in thoracolumbar vertebrae (arrows in A). Typical morphology marked in yellow. Classical "lacy" iliac wings (arrows in B) 
clefts can be seen in dorsolumbar vertebrae [Figure 14].[18] Platyspondyly is usually absent.

\section{Diseases with reduced bone density}

Osteogenesis imperfecta (OI)

Phenotypically and genotypically very heterogeneous; this disease entity can present either in the perinatal period or much later in life with recurrent fractures. The most severe lethal perinatal type 2 OI may not very often undergo radiological imaging. Type 3 OI shows the presence of significant platyspondyly; multiple vertebral body collapses [Figure 15]; evidence of recurrent fractures involving long bones and ribs, multiple wormian bones in the skull. ${ }^{[1,18]}$

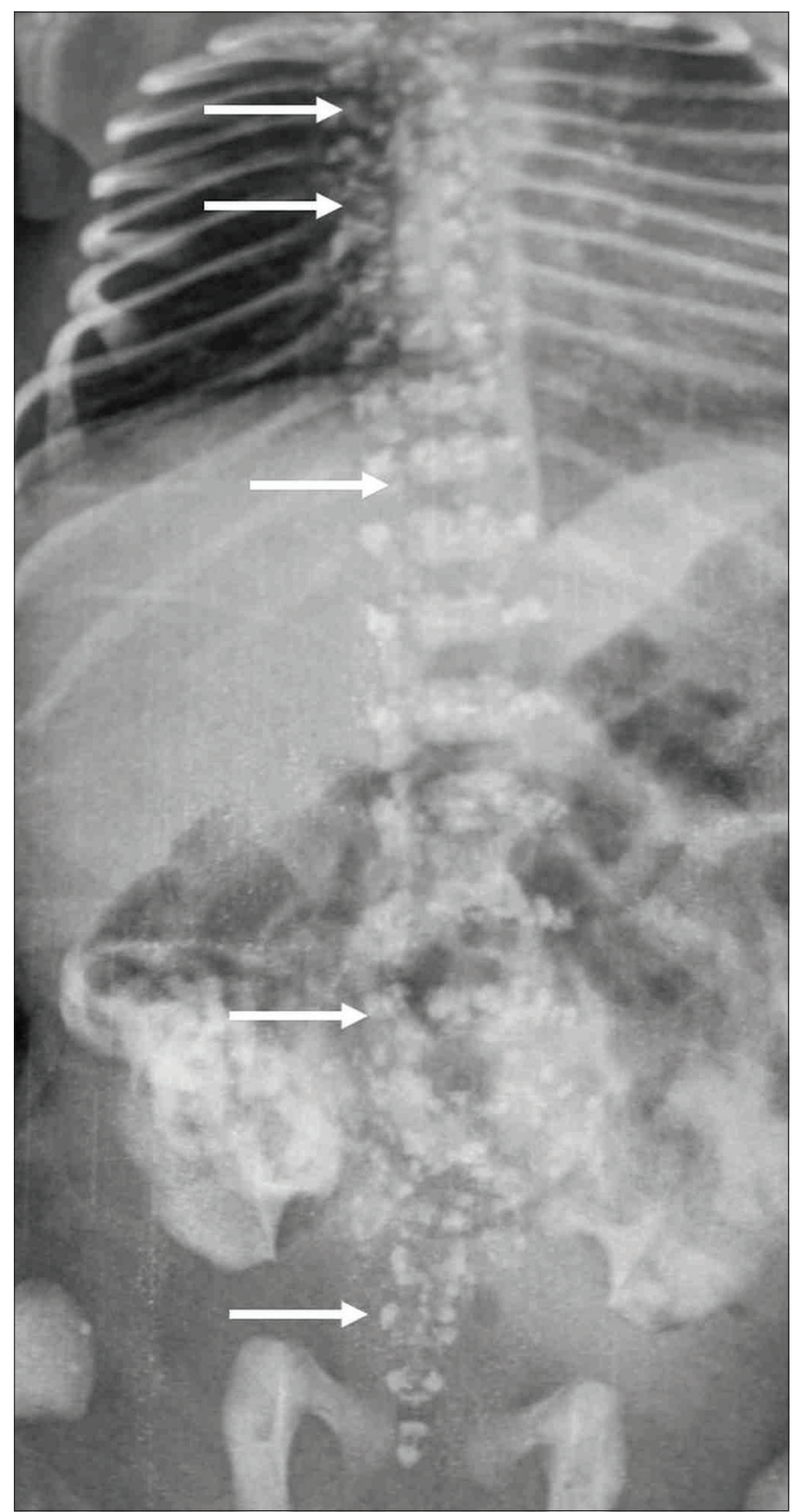

Figure 14: Chondrodysplasia punctata. Extensive stippling involving nearly all vertebral bodies including sacrum (arrows)
Other subtypes may show a milder degree of platyspondyly. Other imaging findings of OI are listed in Table 1.

In a spine radiograph with generalized osteopenia and platyspondyly; it is always prudent to exclude leukemia as a cause, especially in a recent onset platyspondyly.

\section{Achondrogenesis}

This is a lethal skeletal dysplasia. Several different subtypes have been described; types IA, IB, and II. Their radiological phenotypes are different; and so also are the genetic abnormalities. All the three types show absent/very poor ossification of vertebral bodies with ossification of pedicles. Crescent shaped iliac wings and non-ossified skull vault are seen in types IA and IB. Type IA also shows "beaded ribs." Type IB shows widening of cervical and lumbar spinal canals, termed as "cobra-head" appearance [Figure 16]. $\cdot^{[5,27,28]}$ It is important to recognize the findings of undermineralization and platyspondyly on an antenatal sonography.

\section{Hypophosphatasia}

Perinatal hypophosphatasia is a rare lethal skeletal dysplasia characterized by undermineralization of bones. There is poor ossification of neural arches, pedicles, and even entire vertebral bodies. ${ }^{[29]}$ Other imaging findings include shortening and bowing of long bones with diaphyseal "spurs", metaphyseal lucencies, non-ossification involving long bones (missing bones), hypoplastic fibulae, absent skull base ossification, and thin ribs.

Osteopenia with tall vertebral bodies in a child with short stature can be found in $3 \mathrm{M}$ syndrome.

\section{Diseases with increased bone density}

Osteopetrosis

One of the common sclerosing bone dysplasia; this disease presents with hepatosplenomegaly and signs of bone
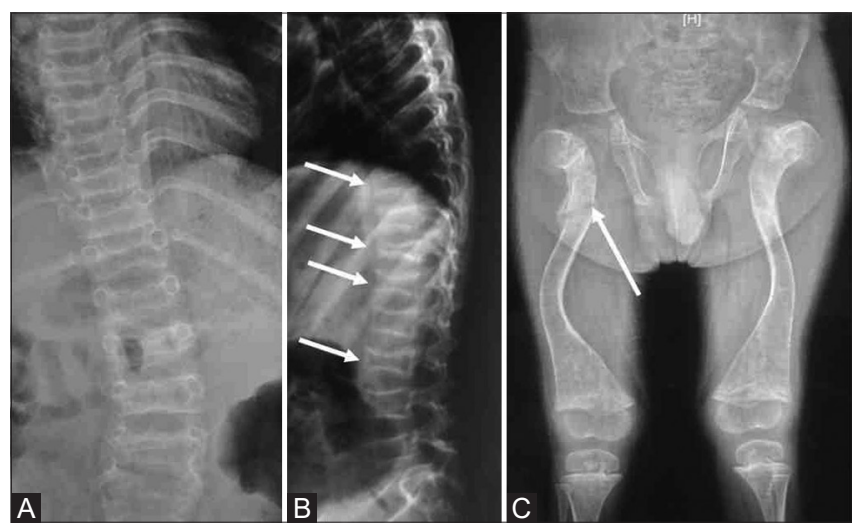

Figure 15 (A-C): (A-C) Osteogenesis imperfecta type 3. Note severe osteopenia and multiple vertebral body collapses (arrows in B) (A and B). Note that owing to osteopenia, it is difficult to differentiate between vertebral body and IV disc space density. Severely deformed long bones with transverse fracture (arrow in C) 
marrow failure. ${ }^{[1]}$ Osteopetrosis has two major types: autosomal recessive (more severe infantile variety) and autosomal dominant variety.

The autosomal dominant variant has two subtypes: I and II. Commonly, the patients present with recurrent fractures, hepatosplenomegaly, and anemia. Multiple cranial nerve compression may occur secondary to skull vault sclerosis. Radiographic features include generalized osteosclerosis, sclerosis of the base of skull (subtype I of autosomal dominant osteopetrosis), multiple fractures involving the long bones.

Spine radiograph shows classical "sandwich" vertebrae, especially in the subtype II autosomal dominant form. ${ }^{[18,30]}$ This appearance refers to a marked sclerosis of the upper and lower endplates [Figure 17]. Other long bones show the classical "bone-within-bone" appearance.

The autosomal recessive variant of osteopetrosis has more severe clinical manifestations early in infancy. They present with failure to thrive, hepatosplenomegaly, anemia and pancytopenia, and features of cranial nerve entrapment. Radiographic features include generalized osteosclerosis,

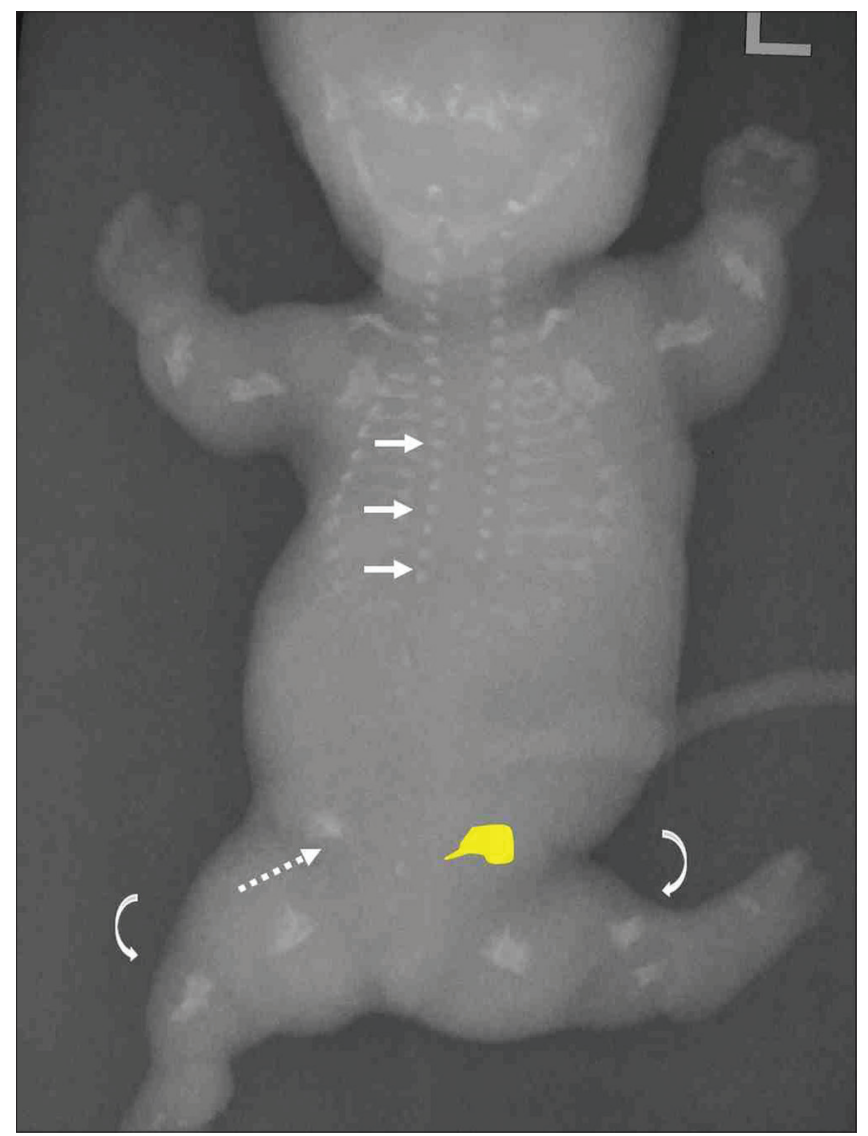

Figure 16: Achondrogenesis type IB. infantogram in a stillborn fetus shows non-ossified vertebral bodies and visualization of the pedicles (arrows), crescent shaped iliac wing (dotted arrow and marked in yellow), severe micromelia (curved arrows), no beading of the ribs obliteration of marrow cavity, bone-within-bone appearance, and calvarial sclerosis. Renal tubular acidosis may be associated.

\section{Pyknodysostosis}

This is another sclerosing bone dysplasia and considered in a differential diagnosis of osteopetrosis on radiographs. The clinical presentations are different from that of osteopetrosis. Usually there is no hepatosplenomegaly or anemia. ${ }^{[1]}$ On radiographs, medullary cavities of the long bones are preserved. Differentiation from osteopetrosis solely on the basis of spinal radiograph is not often possible. Typical imaging findings include "spool shaped" vertebrae, ${ }^{[31]}$ acro-osteolysis of distal phalanges of hands/ feet, obtuse mandibular angles, and wide open cranial sutures [Figure 18]. ${ }^{[32]}$

Diseases with more focal/localized involvement of the vertebral column

This group predominantly involves the vertebral segmentation anomalies; which can be isolated or as a part of some defined syndromes. Isolated segmentation anomalies of one vertebral body in the form of a butterfly vertebra or hemivertebra may be an isolated finding; however, in presence of specific clinical morphologic markers, they may be significant.

Multiple vertebral segmentation anomaly is more suggestive of a syndromic association.

\section{Klippel-Feil syndrome}

Usually presents as a short neck, low hairline and restriction of neck movements. On radiographs, there are usually
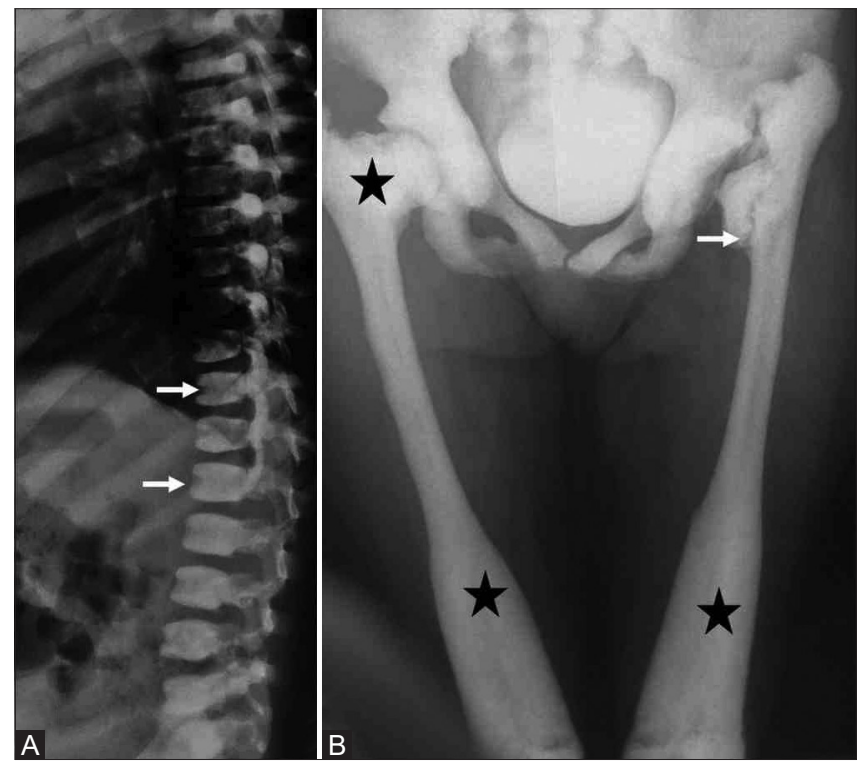

Figure 17 (A and B): (A and B) Osteopetrosis. Classical "sandwich vertebrae" (arrows in a). Extensive bony sclerosis and obliteration of marrow cavity (asterisk in B). Note fracture of left femoral neck (arrow in B) 

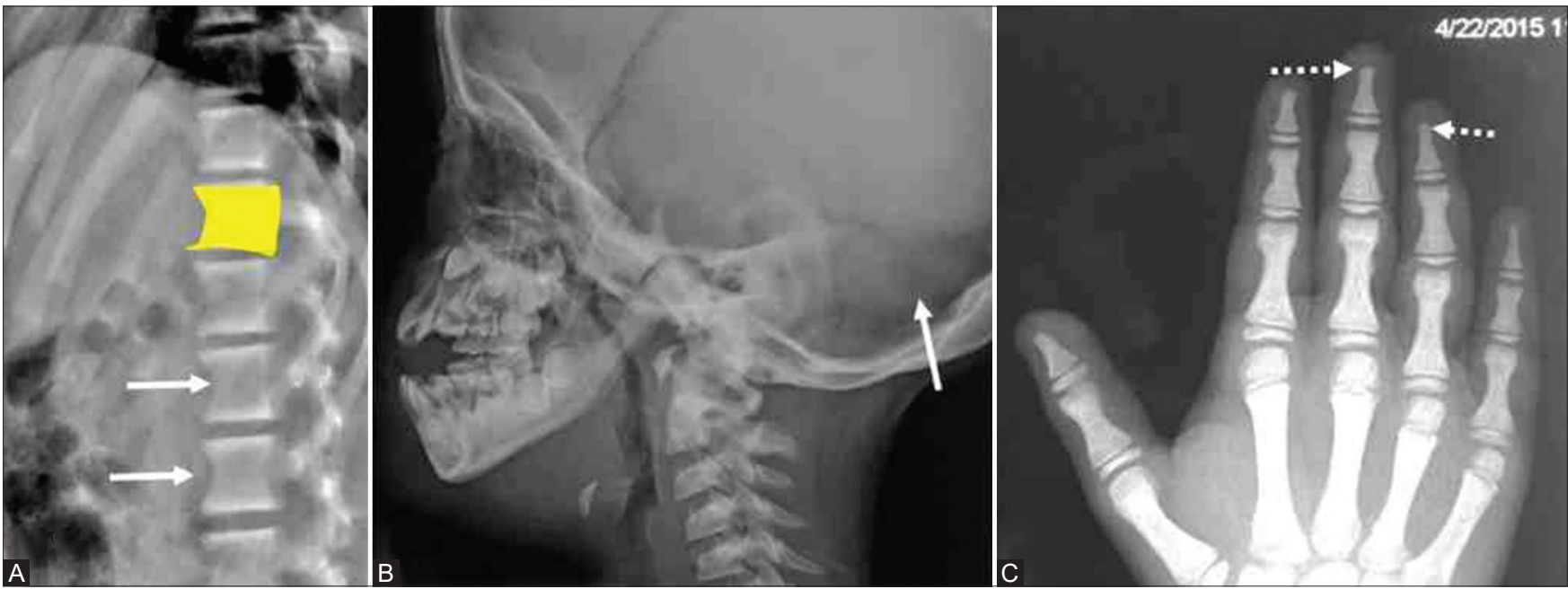

Figure 18 (A-C): (A and C) Pyknodysostosis. Osteosclerosis and spool shaped vertebrae (arrows in A, and marked in yellow). Associated findings are obtuse mandibular angle (B), wide open lambdoid suture (arrow in B) and acroosteolysis (dotted arrow in C)

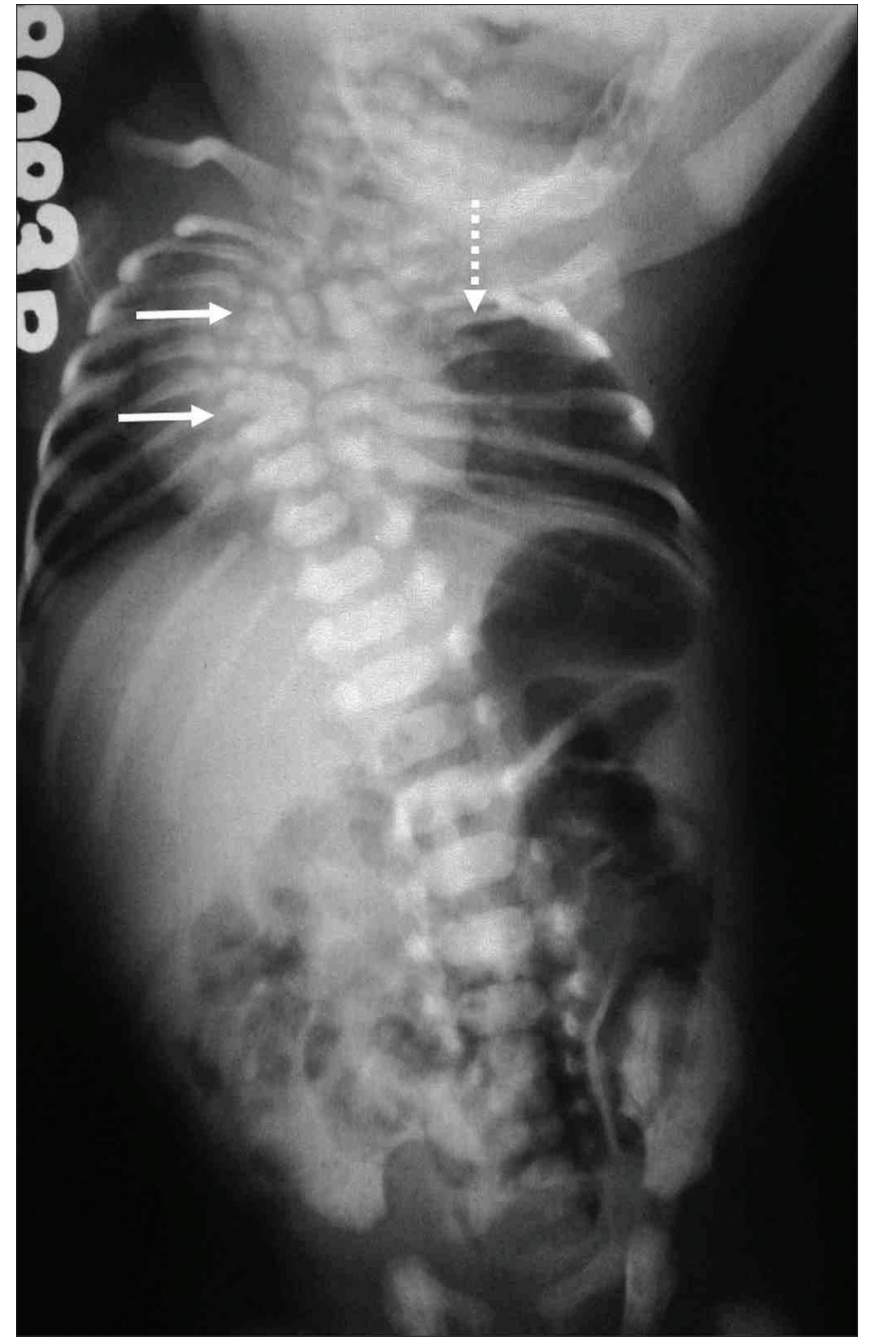

Figure 19: Spondylocostal dysostosis 4. Multiple vertebral segmentation anomalies (arrows) and associated rib anomalies (dotted arrow). Note the prominent pedicles giving rise to "tram track appearance". Lumbar vertebrae are normal multiple cervical vertebral segmentation anomalies, an abnormal bony bar (omovertebral bar) connecting a high-up and small malaligned scapula.

\section{Spondylocostal dysostosis}

This is a heterogeneous group of disorder characterized by multiple vertebral segmentation anomalies $(>/=10)$, and associated rib anomalies (fusion/absence/malalignment). The thoracic cavity is mostly symmetrical in these groups of disorders. The spondylocostal dysostosis type 1 is also known as Jarcho-Levin syndrome and is characterized by severe shortening of the axial skeleton resulting in a "crab-like chest." The typical radiological appearance of SCD type 1 is a "pebble like" appearance of the vertebral bodies; whereas in SCD type 4 the classical appearance described is a "tramline" appearance [Figure 19] secondary to the prominent pedicles. ${ }^{[33]}$

There are several diagnostic algorithms ${ }^{[33]}$ described for analysis of vertebral segmentation anomalies, detailed description of which is beyond the scope of this article.

\section{Approach to a Spine Radiograph in Suspected Dysplasia}

In a suspected skeletal dysplasia, it is always essential to exclude the presence of metabolic diseases first. Whenever assessing a spine radiograph, bone density and bony trabeculae should be assessed first. Systematic evaluation of vertebral height and morphology should be assessed next. Any classical imaging finding as described above should be correlated with other radiographs of the skeletal survey. A suggested simplified approach is provided in Figures 20 and 21. 


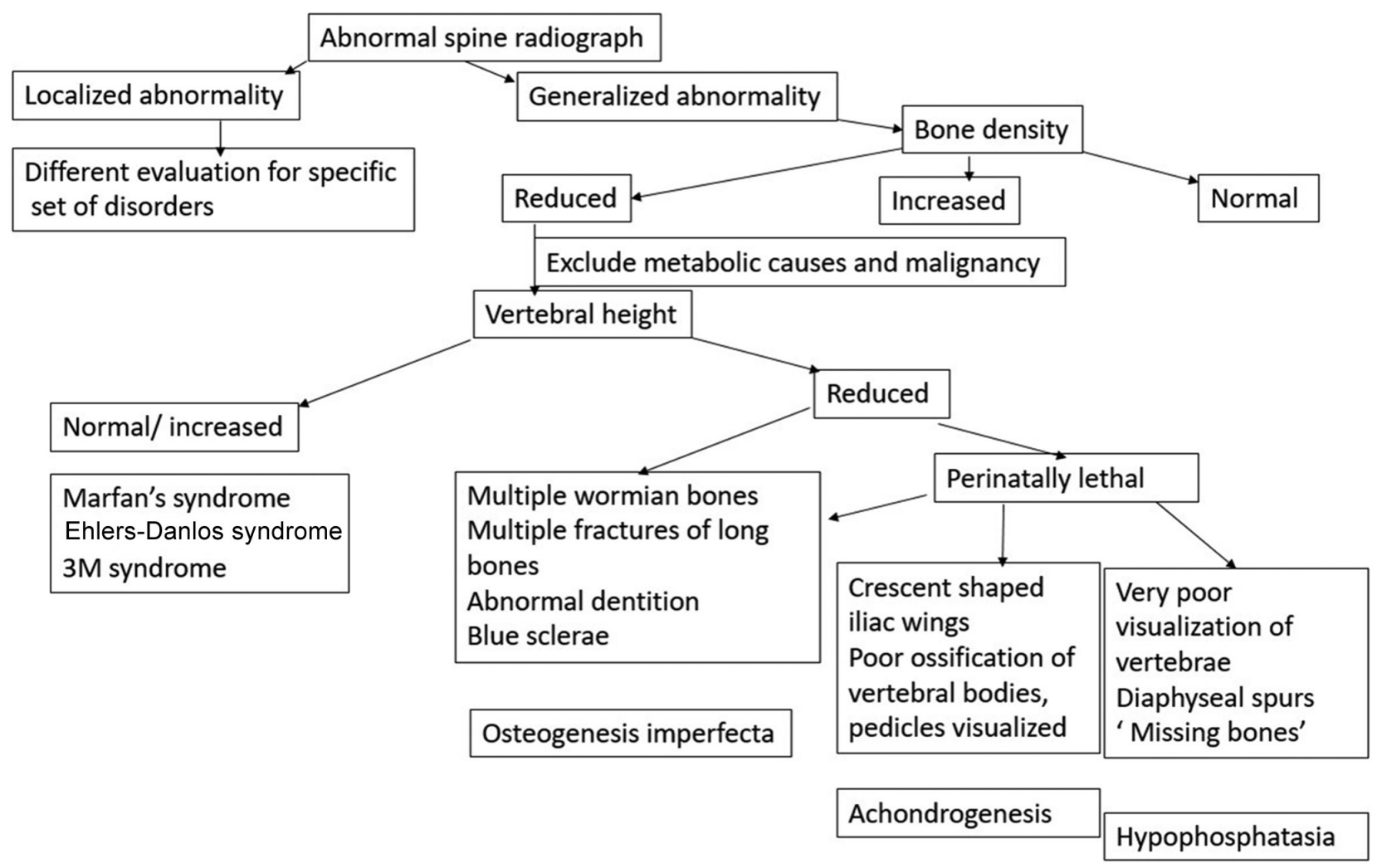

Figure 20: Approach to an abnormal spine radiograph with reduced bone density

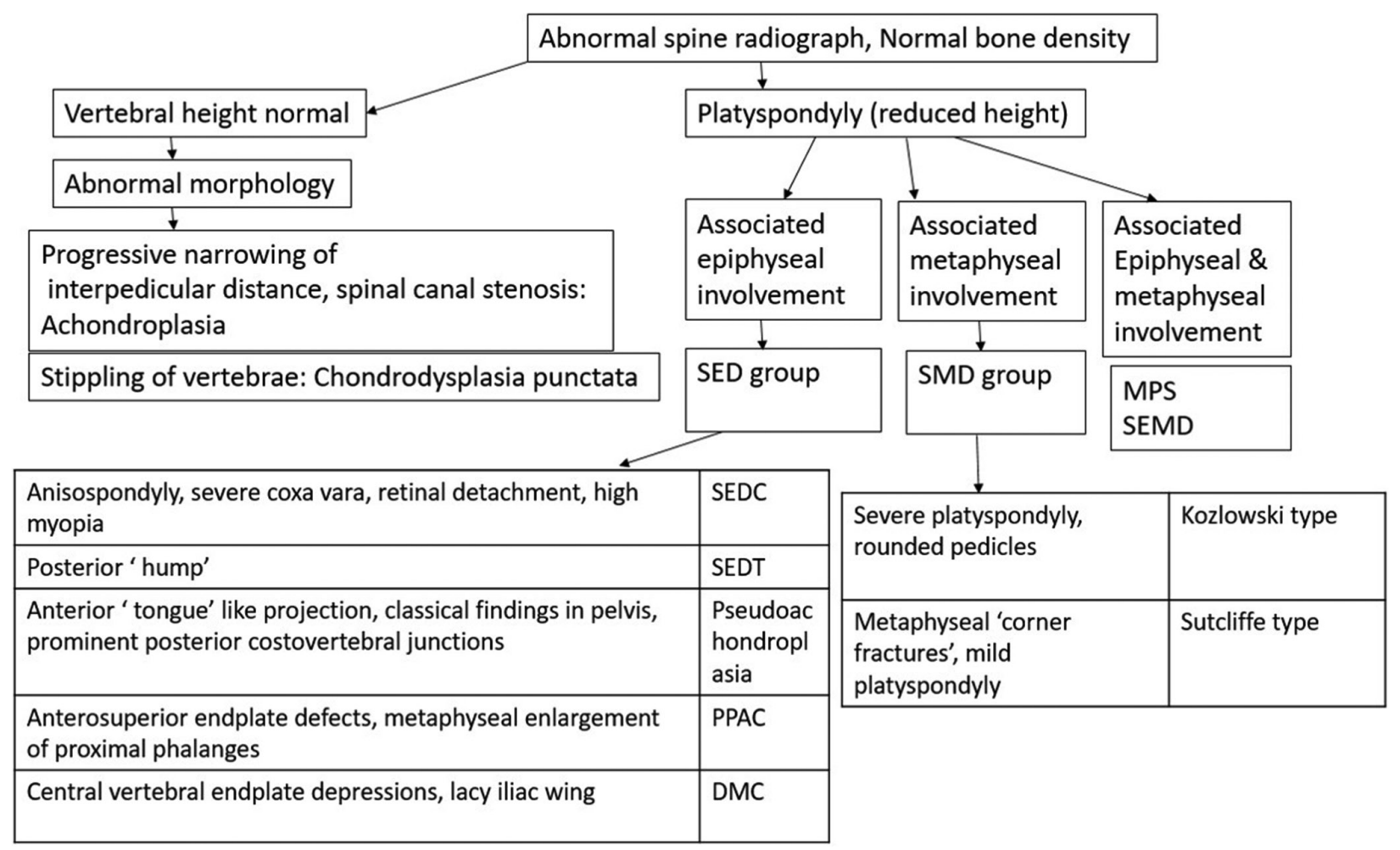

DMC: Dyggve-Melchior-Claussen syndrome,PPAC: Progressive pseudorheumatoid arthropathy of childhood,

MPS: mucopolysaccharoidosis, SED: Spondyloepihyseal dysplasia, SEDC: Spondyloepiphyseal dysplasia congenita,

SEMD: Spondyloepipmetahyseal dysplasia, SEDT: Spondyloepiphyseal dysplasia tarda

Figure 21: Suggested approach to an abnormal spine radiograph in suspected skeletal dysplasia; with normal bone density 


\section{Conclusion}

Skeletal survey is an integral part of evaluation in suspected skeletal dysplasia and spine radiograph is an important component of it. However, sometimes spine radiograph alone, performed for some other indications may provide useful insight into the underlying dysplasia. A systematic evaluation of the spine radiograph can provide important diagnostic information in reaching a close differential diagnosis; and sometimes a specific diagnosis.

\section{Financial support and sponsorship}

Nil.

\section{Conflicts of interest}

There are no conflicts of interest.

\section{References}

1. Christ B, Scaal M. Development of the back. In: Standring S, editor. Gray'sAnatomy: The Anatomical Basis of Clinical Practice. $41^{\text {sted. }}$ New York: Elsevier Limited; 2016. p. 756.

2. Budorick NE, Pretorius DH, Grafe MR, Lou KV. Ossification of the fetal spine. Radiology 1991;181:561-5.

3. Mortier GR, Cohn DH, Cormier- Daire V, Hall C, Krakow D, Mundlos S, et al. Nosology and classification of genetic skeletal disorders: 2019 revision. Am J Med Genet A 2019;179:2393-419.

4. Dighe M, Fligner C, Cheng E, Warren B, Dubinsky T. Fetal skeletal dysplasia: An approach to diagnosis with illustrative cases. Radiographics2008;28:1061-77.

5. Hall CM, Offiah AC, Forzano F, Lituania M, Fink M, Krakow D, editors.Fetal and Perinatal Skeletal Dysplasias: An Atlas of Multimodality Imaging. $1^{\text {st }}$ ed.London: Radcliffe Publishing Limited; 2012.

6. Pauli RM. Achondroplasia: Acomprehensive clinical review. Orphanet J Rare Dis 2019;14:1.

7. Fasanelli S. Hypochondroplasia: Radiological diagnosis and differential diagnosis. Basic Life Sci 1988;48:163-6.

8. Schramm T, Gloning KP, Minderer S, Daumer-Haas C, Hörtnagel $\mathrm{K}$, Nerlich A, et al. Prenatal sonographic diagnosis of skeletal dysplasias. Ultrasound ObstetGynecol 2009;34:160-70.

9. Weiner DS, Guirguis J, Makowski M, Testa S, Shauver L, Morgan D. Orthopaedic manifestations of pseudoachondroplasia. J Child Orthop 2019;13:409-16.

10. Posey KL, Alcorn JL, Hecht JT. Pseudoachondroplasia/ COMP-translating from the bench to the bedside. Matrix Biol 2014;37:167-73.

11. Chen SJ, Li YW, Wang TR, Hsu JC. Bony changes in common mucopolysaccharidoses. Zhonghua Min GuoXiao ErKe Yi Xue Hui ZaZhi1996;37:178-84.

12. Grech R, Galvin L, O'Hare A, Looby S. Hurler syndrome (Mucopolysaccharidosis type I). BMJ Case Rep 2013;2013:bcr2012008148.doi: 10.1136/bcr-2012-008148.

13. Sawamoto K, Álvarez González JV, Piechnik M, Otero FJ, Couce ML, Suzuki Y, et al. Mucopolysaccharidosis IVA: Diagnosis, treatment, and management. Int J MolSci 2020;21:1517.

14. David-Vizcarra G, Briody J, Ault J, Fietz M, Fletcher J, Savarirayan R, et al. The natural history and osteodystrophy of mucolipidosis types II and III. J Paediatr Child Health 2010;46:316-22.

15. Nenna R, Turchetti A, Mastrogiorgio G, Midulla F. COL2A1 gene mutations: Mechanisms of spondyloepiphyseal dysplasia congenita. ApplClin Genet 2019;12:235-8.

16. Terhal PA, Nievelstein RJAJ, Verver EJJ, Topsakal V, van Dommelen $\mathrm{P}$, Hoornaert $\mathrm{K}$, et al. A study of the clinical and radiological features in a cohort of 93 patients with a COL2A1 mutation causing spondyloepiphyseal dysplasia congenita or a related phenotype. Am J Med Genet A 2015;167A: 461-75.

17. Spranger JW, Langer LO.Spondyloepiphyseal dysplasia congenita. Radiology 1970;94:313-22.

18. Panda A, Gamanagatti S, Jana M, Gupta AK. Skeletal dysplasias: A radiographic approach and review of common non-lethal skeletal dysplasias. World J Radiol 2014;6:808-25.

19. el-Shanti HE, Omari HZ, Qubain HI. Progressive pseudorheumatoid dysplasia: Report of a family and review. J Med Genet 1997;34:559-63.

20. Spranger J, Albert C, Schilling F, Bartsocas C. Progressive pseudorheumatoidarthropathy of childhood (PPAC): Ahereditary disorder simulating juvenile rheumatoid arthritis. Am J Med Genet 1983;14:399-401.

21. Torreggiani S, Torcoletti M, Campos-Xavier B, Baldo F, Agostoni C, Superti-Furga A, et al. Progressive pseudorheumatoid dysplasia: Arare childhood disease. RheumatolInt 2019;39:441-52.

22. Nair N, Satapathy AK, Gupta N, Kabra M, Gupta AK, Jana M. Spondylometaphysealdysplasia corner fracture (Sutcliffe) type. Indian J Pediatr 2016;83:1191-4

23. Nural MS, Diren HB, Sakarya O, Yalin T, Dağdemir A. Kozlowski type spondylometaphyseal dysplasia: Acase report with literature review. DiagnIntervRadiol 2006;12:70-3.

24. Unger S, Bonafé L, Superti-Furga A. Multiple epiphyseal dysplasia: Clinical and radiographic features, differential diagnosis and molecular basis. Best Pract Res ClinRheumatol 2008;22:19-32.

25. Dyggve HV, Melchior JC, Clausen J, Rastogi SC. The Dyggve-Melchior-Clausen (DMC) syndrome.A 15 year follow-up and a survey of the present clinical and chemical findings. Neuropadiatrie 1977;8:429-42.

26. Seguin JH, Baugh RF, McIntee RA. Airway manifestations of chondrodysplasia punctata.Int J PediatrOtorhinolaryngol 1993;27:85-90.

27. Jiminez RB, Holmes LB, Kaiser JS, Weber AL. Achondrogenesis. Pediatrics 1973;51:1087-90.

28. Nampoothiri S. Six lethal skeletal dysplasias which a pediatrician should never miss. Genetic Clinics 2015;8:12-5.

29. Offiah AC, Vockley J, Munns CF, Murotsuki J. Differential diagnosis of perinatal hypophosphatasia: Radiologic perspectives. PediatrRadiol 2019;49:3-22.

30. Wu CC, Econs MJ, DiMeglio LA, Insogna KL, Levine MA, Orchard PJ, et al. Diagnosis and management of osteopetrosis: Consensus guidelines from the osteopetrosis working group. J ClinEndocrinolMetab 2017;102:3111-23.

31. Rajan AR, Singh V, Bhave AA, Joshi CS. Pycnodysostosis: A rare cause of short stature. Med J Armed Forces India 2015;71:393-5.

32. Ramachandran S, Vijayabala GS. Pycnodysostosis- Areview. Southeast Asian J Case Rep Rev 2012;1:42-5.

33. Offiah A, Alman B, Cornier AS, Giampietro PF, Tassy O, Wade A, et al. Pilot assessment of a radiologic classification system for segmentation defects of the vertebrae. Am J Med Genet A 2010;152A: 1357-71. 